\title{
TJALLING C. KOOPMANS ECONOMETRIC THEORY PRIZE 2015-2017
}
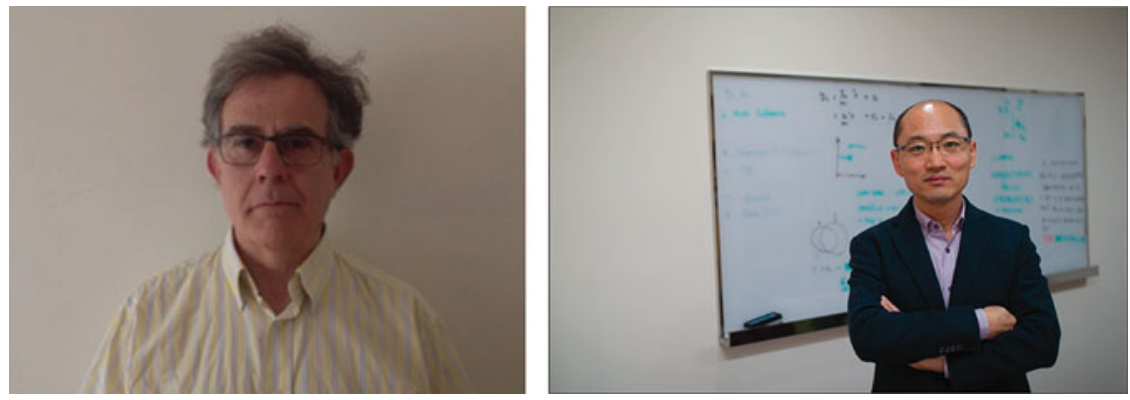

Econometric Theory is proud to announce the winning article for "The Tjalling C. Koopmans Econometric Theory Prize" over the period 2015-2017 inclusive. The prize is kindly supported by the Cowles Foundation, Yale University. It is named in honor of Tjalling C. Koopmans, the 1975 Nobel Laureate in Economic Science. The selection of the winning article was made by the Advisory Board of the Journal and all articles published in Econometric Theory over 2015-2017 inclusive were candidates for the prize, except those that were authored or coauthored by the Editor and members of the Advisory Board. The prize is accompanied by a financial award of $\$ 1000$ to the winning author(s).

The winning article and citation (written by the Advisory Board and Editor) are as follows:

Javier Hidalgo and Myung Hwan Seo are awarded the Tjalling C. Koopmans Econometric Theory Prize for the article

"Specification Tests for Lattice Processes," Econometric Theory, April 2015, volume 31(2), pages 294-336.

\section{Citation}

The article explores the properties of weakly stationary (scalar) random sequences $\mathrm{x}(\mathrm{t})$ in which the parameter $(\mathrm{t})$ may be $\mathrm{d}$ dimensional on a lattice. Important examples are, for $\mathrm{d}=1$, noncausal linear dynamical systems and, for $\mathrm{d}>1$, spatial and spatiotemporal systems, which play a major role in many scientific areas. Many relevant examples of such processes arise in environmental and development economics. Within this wide context, $\mathrm{x}(\mathrm{t})$ is assumed to be a generalized "spatial" linear process, with unobserved "spatial" i.i.d. inputs. This 
formulation leads to a transfer function in $\mathrm{d}$ variables and a spectral density in $\mathrm{d}$ variables. The article contributes by developing statistical tests for correct specification of the dynamics of $\mathrm{x}(\mathrm{t})$, or more precisely, tests of the hypothesis that the covariogram of $\mathrm{x}(\mathrm{t})$ follows a specific parametric model. The (tapered) periodogram may be used for a Whittle-type estimator leading to a corresponding test. Such a test-statistic, however, is not pivotal. To address this difficulty, the authors introduce a transformation that leads to an asymptotic distribution, which is free of nuisance parameters. As a second result, the authors propose a bootstrap analogue of the transformation and confirm its validity. Third, the authors analyze linear parametric regression models, where $\mathrm{x}(\mathrm{t})$ is the (unobserved) additive noise component. These contributions provide a foundation for further study of such multidimensional spatiotemporal processes and a mechanism for their use in econometric work in many different applied fields.

Cambridge University Press joins me in congratulating the authors on their success in receiving this award.

Peter C.B. Phillips April 2018 